\title{
Acute attack of recurrent esophageal duplication cyst in an adult: case report and literature review
}

\author{
Xinchun Duan ${ }^{1}$, Yong $\mathrm{Cui}^{2}$, Ying $\mathrm{He}^{2}$, Shaofa $\mathrm{Xu}^{1}$ \\ ${ }^{1}$ Department of Thoracic Surgery, Beijing Chest Hospital, ${ }^{2}$ Department of Thoracic Surgery, Beijing Friendship Hospital, Capital Medical \\ University, Beijing, China \\ Correspondence to: Yong Cui, MD. Department of Thoracic Surgery, Beijing Friendship Hospital, Capital Medical University, No. 59, Yongan Road, \\ Xicheng District, Beijing 100050, China. Email: cywork1@sina.com.
}

Submitted Oct 30, 2017. Accepted for publication Mar 22, 2018.

doi: $10.21037 /$ jtd.2018.04.89

View this article at: http://dx.doi.org/10.21037/jtd.2018.04.89

\section{Introduction}

Esophageal duplication cyst (EDC) is an uncommon, usually asymptomatic congenital benign esophageal tumor that was first described by Blassium in 1711 (1). The etiology of EDC is a failure of vacuolization in the primitive foregut during the fourth to eighth week of embryonic development (2). It accounts for $10-15 \%$ of all alimentary tract duplications, but only $0.5-2.5 \%$ of esophageal tumors (3). Almost $80 \%$ of EDC becomes symptomatic and is discovered in early childhood, but in a few patients, EDC remains asymptomatic until adulthood (2). It can usually be cured by surgical resection $(4,5)$, and only one recurrent case has been reported (6) (PubMed database). Furthermore, only five cases (Table 1) of acute onset of EDC in adults have been described in the literature $(2,3,5,7,8)$ (PubMed database). Here, we describe a case of postoperative recurrent EDC accompanied by acute symptoms.

\section{Case presentation}

A 54-year-old man was admitted to the emergency department of Beijing Friendship Hospital on November 14, 2014, with complaints of acute chest pain and severe dysphagia. He stated he had mild dysphagia for nearly 1 week, and then the dysphagia was suddenly aggravated by intermittent nausea and vomiting such that he could not eat and drink. We used morphine to help relive the patient from persistent chest pain and parenteral alimentation to support nutrition. Past medical history showed previous surgical enucleation for EDC (Table 2) at the Beijing
Tongren Hospital in 1982.

On physical examination, a previous surgical incision scar of approximately $40 \mathrm{~cm}$ was observed on the posterior wall of the left chest. Blood test revealed a significantly elevated level of leukocytosis $\left(10.9 \times 10^{9} / \mathrm{L}\right)$ and neutrophil percentage $(87.2 \%)$. The other meaningful results were hemoglobin $(113 \mathrm{~g} / \mathrm{L})$ and platelet $\left(98 \times 10^{9} / \mathrm{L}\right)$ concentrations. A chest CT showed a $9.1 \times 4.7 \times 17 \mathrm{~cm}^{3}$ soft tissue mass in the lower-middle esophagus associated with upper esophageal dilatation and air-fluid level. The main bronchi, pulmonary artery, and pulmonary vein were all compressed, and pneumonia with a small amount of right pleural effusion was present (Figure 1A,B,C,D). Endoscopic ultrasound (EUS) revealed hypoechoic lesions originating from the esophageal muscularis propria with unclear margins (Figure 1E,F).

Due to uncertain diagnosis and life-threatening symptoms, a right-side exploratory thoracotomy was undertaken, and a large cystic-solid mass with high tension located in the lower-middle esophagus was found. The lesions occupied nearly the entire length of the esophagus and were adhered to trachea, venae azygos, pericardium, and inferior pulmonary veins. We then made a small incision from the protruded part of cyst and aspirated approximately $200 \mathrm{~mL}$ of dark-brown clotted blood, which was immediately followed by a quick drop in the previously elevated tension. However, multiple cysts and inflammatory dense adhesions between the cyst wall and the esophageal muscle layer were found. Therefore, we performed a midline laparotomy and removed the diseased esophagus (Figure 2A), making a tubular gastric and gastroesophageal 
Table 1 Published case reports of acute esophageal duplication cyst in adult

\begin{tabular}{|c|c|c|c|c|c|c|c|c|c|}
\hline Case & Reference & Year & Age & Sex & Symptoms & Complication & Location & Size $(\mathrm{cm})$ & Treatment \\
\hline 2 & $\begin{array}{l}\text { Nakahara } \\
\text { Ket al. (8) }\end{array}$ & 1990 & 36 & $\mathrm{~F}$ & $\begin{array}{l}\text { Acute dysphagia and } \\
\text { dyspnea }\end{array}$ & Rupture & Middle mediastinum & $8 \times 8$ & $\begin{array}{l}\text { Thoracotomy, } \\
\text { enucleation }\end{array}$ \\
\hline 4 & $\begin{array}{l}\text { Pisello F } \\
\text { et al. (3) }\end{array}$ & 2009 & 46 & M & Acute dysphagia & Hemorrhage & $\begin{array}{l}\text { Posterior wall of the } \\
\text { middle esophagus }\end{array}$ & $6 \times 8.5$ & $\begin{array}{l}\text { Thoracotomy, } \\
\text { enucleation }\end{array}$ \\
\hline 5 & $\begin{array}{l}\text { Wang D } \\
\text { et al. (2) }\end{array}$ & 2015 & 52 & $\mathrm{~F}$ & $\begin{array}{l}\text { Rapidly progressing chest } \\
\text { pain and dysphagia }\end{array}$ & $\begin{array}{l}\text { Inflammatory } \\
\text { dense adhesions }\end{array}$ & $\begin{array}{l}\text { Lower part of the } \\
\text { esophagus }\end{array}$ & $10 \times 6 \times 4$ & $\begin{array}{l}\text { Thoracotomy, } \\
\text { esophagectomy }\end{array}$ \\
\hline
\end{tabular}

$\mathrm{M}$, male; $F$, female.

Table 2 Summary of the patient's clinical data

\begin{tabular}{|c|c|c|c|c|c|c|c|}
\hline Year & Age & Symptoms & Primary check & Treatment & Cystic contents & Pathology & Hospital \\
\hline 2014 & 54 & $\begin{array}{l}\text { Acute chest } \\
\text { pain and severe } \\
\text { dysphagia }\end{array}$ & $\begin{array}{l}\text { Chest computed tomography showed a } \\
9.1 \times 4.7 \times 17 \mathrm{~cm}^{3} \text { soft tissue mass in the } \\
\text { lower-middle esophagus }\end{array}$ & $\begin{array}{l}\text { Right posterolateral } \\
\text { and abdominal } \\
\text { median incision, } \\
\text { esophagectomy }\end{array}$ & $\begin{array}{l}\text { Dark-brownish } \\
\text { blood clots } \\
\text { (>200 mL) }\end{array}$ & $\begin{array}{l}\text { Recurrent } \\
\text { esophageal } \\
\text { duplication cyst }\end{array}$ & $\begin{array}{l}\text { Beijing } \\
\text { Friendship } \\
\text { Hospital }\end{array}$ \\
\hline
\end{tabular}

anastomosis at the top of the chest. Postoperative pathology confirmed the diagnosis of recurrent EDC (Figure 2B,C), which was consistent with the pathological diagnosis 32 years ago (Figure 2D,E).

Postoperative barium esophagography showed no complications. The patient was discharged with an uneventful recovery on the 15 th postoperative day. During the 36 months of follow-up, only slight acid reflux esophagitis was observed, and the symptoms improved after taking omeprazole $(20 \mathrm{mg} / \mathrm{d})$.

\section{Discussion}

The predilection site of EDC is the right posteroinferior mediastinum or lower-middle esophagus (3). Most EDCs present in isolation, while some develop as multiple cysts (9). Cysts of different sizes and locations may cause various symptoms such as cough, recurrent pneumonitis, chest pain, dysphagia, and dyspnea $(2,3,7)$. As the cysts continue to develope, it might become acutely enlarged, leading to life-threatening complications such as rupture, obstruction, hemorrhage, and malignancy $(2,3,5,7,8,10)$.

Preoperative diagnosis of EDC usually needs a combination of various imaging techniques. Chest roentgenology, barium examination, and chest CT are the basic examinations performed before EDC surgery. Magnetic resonance imaging (MRI) has high diagnostic value in identifying cystic or solid tumors, especially for cystic fluid. Endoscopic ultrasound (EUS) can effectively evaluate these lesions and show if the cysts are anechoic or hypoechoic, In EUS, thin-walled cystic structures are the most common sign of EDC (9). EUS-guided fine needle aspiration biopsy can offer a quick and accurate qualitative diagnosis, but it may increase the risk of future surgery (11). Histopathological diagnose of EDC should follow Palmer's three criteria (12): (I) adhere to or in the esophageal wall; (II) covered by gastrointestinal tract epithelium such as squamous, columnar, cuboid, pseudostratified, or ciliated 

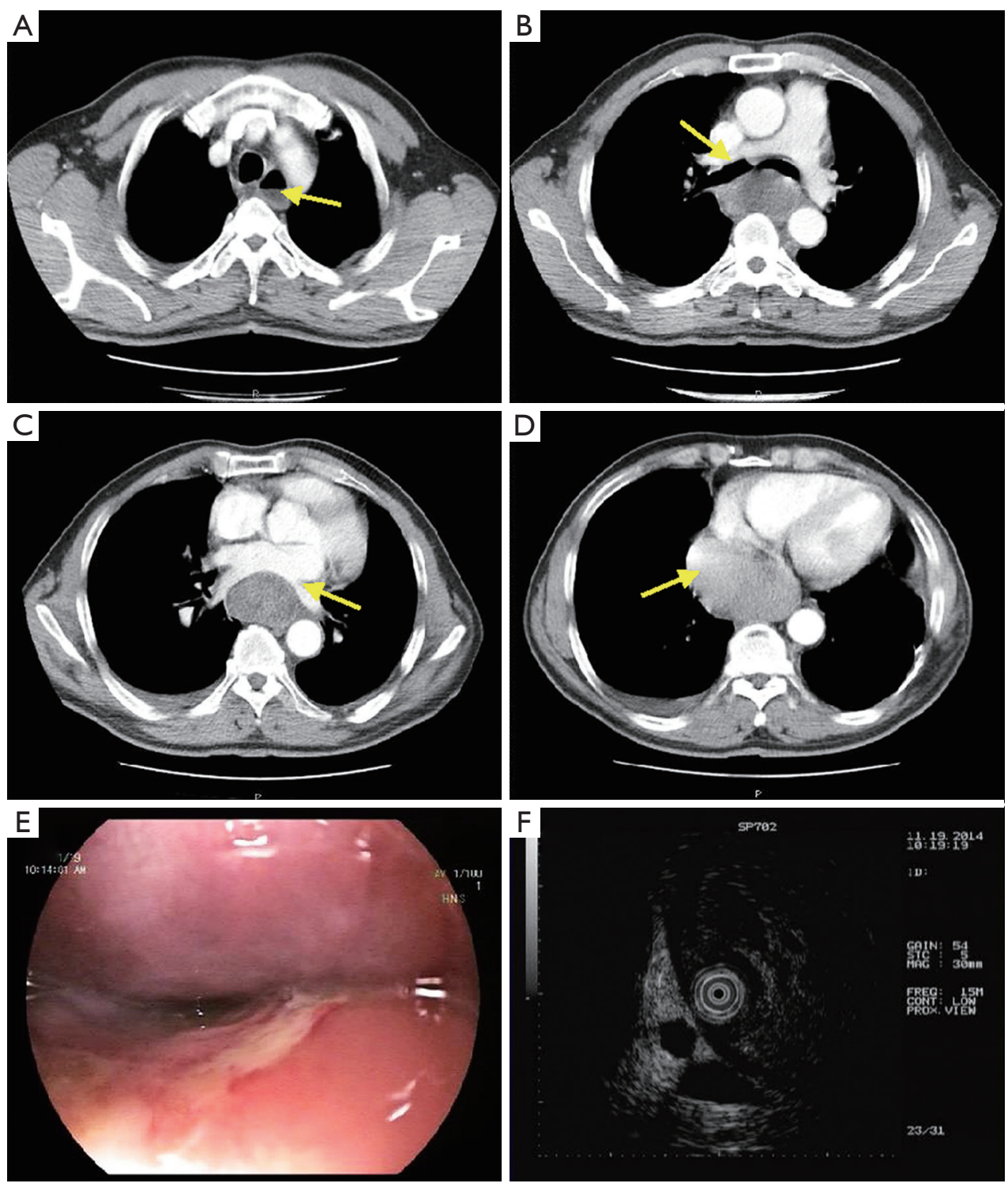

Figure 1 Chest CT demonstrated a $9.1 \times 4.7 \times 17 \mathrm{~cm}^{3}$ soft tissue mass in the lower-middle esophagus (D) with upper esophageal dilatation and air-fluid level (A). The bronchi and pulmonary artery/vein (B and C) were compressed. EUS revealed hypoechoic lesions associated with unclear margins ( $\mathrm{E}$ and $\mathrm{F})$.

epithelium; and (III) double layer muscularis propria under epithelium.

As the preferred treatment for EDC, surgical resection has the advantages of definitive diagnosis and relieving existing symptoms and can prevent future serious complications. The surgical approach includes thoracotomy and minimally invasive surgery, such as videoassisted thoracoscopic surgery and endoscopic submucosal dissection (13). The reasonable surgical option should be determined according to the size and location of the cyst and its relation to adjacent tissue and organs.

The preoperative diagnosis in this case was difficult because the conclusions drawn from the various inspections were equivocal. The final pathological diagnosis was recurrent EDC. We suspect the recurrence is attributed to failure of the initial surgery to completely remove the cyst itself or perhaps smaller cysts that might have been adjacent to the resected lesion. It is important to emphasize 


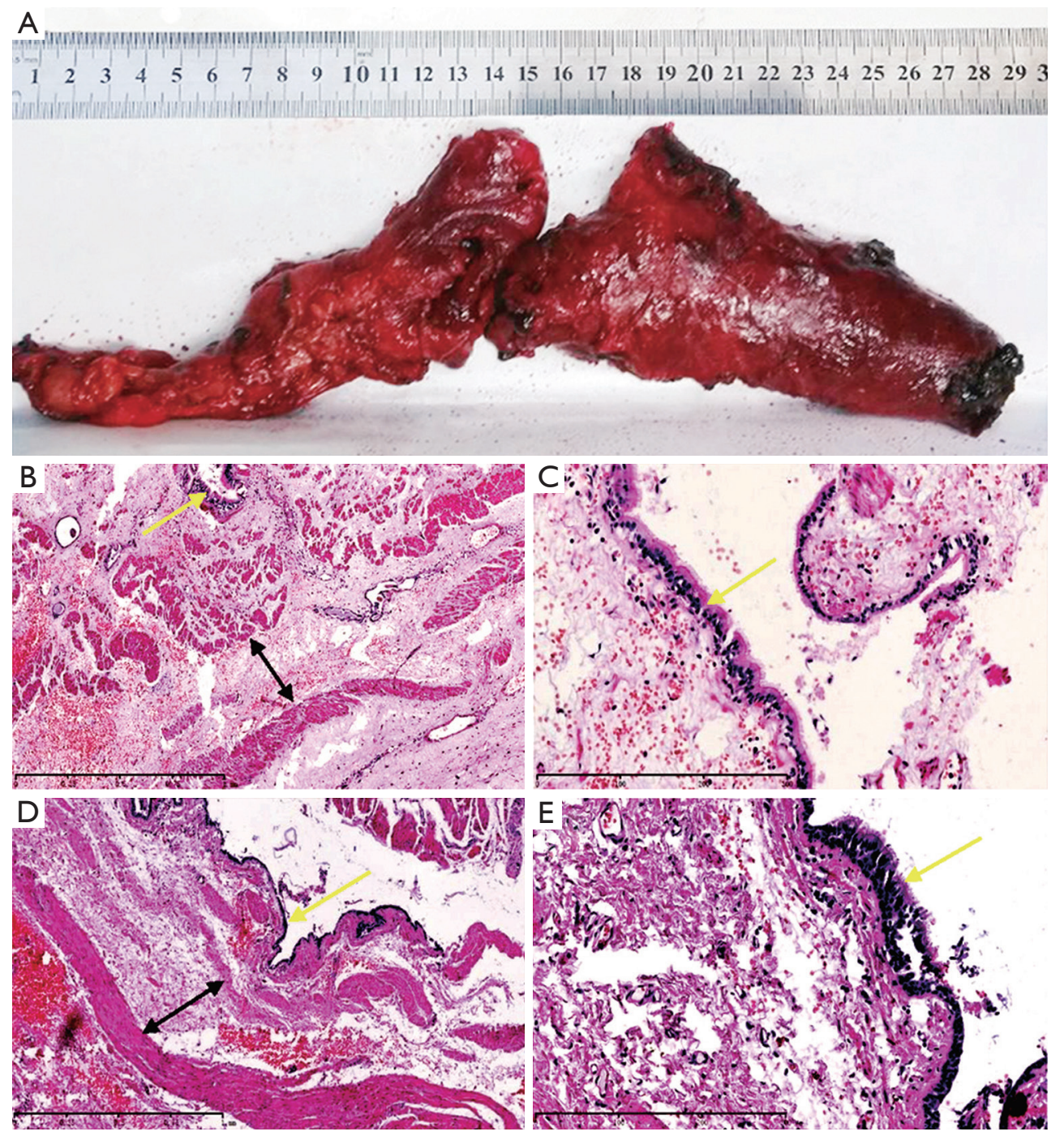

Figure 2 The resected specimen of the postoperative recurrent EDC (A) and pathology (B and C). The patient's first EDC pathology (D and $\mathrm{E}$ ). (hematoxylin and eosin staining, $\mathrm{B}$ and $\mathrm{D} \times 50, \mathrm{C}$ and $\mathrm{E} \times 200$ ). Both pathological examinations showed pseudostratified columnar ciliated epithelium (yellow arrow) with two layers of muscularis propria underneath (black arrow).

that an esophageal cyst is not a recurrent disease, such as a malignant tumor, but may have recurrent features when the surgical treatment is incomplete. In addition to the recurrence of EDC, another point of our report is the rapid progression of symptoms. Only five similar cases have been reported (Table 1). After reviewing these cases, we can conclude that acute EDC has the following features: (I) acute dysphagia and chest pain are the most common symptoms. Symptoms in the course of disease progression start from mild to acute exacerbation and then are suddenly alleviated due to rupture; (II) large size; (III) secretion or hemorrhage in a cyst, which may be the main reason why preoperative diagnosis is difficult; (IV) severe complications; and (V) inflammatory adhesions. Given all these characteristics, thoracotomy is advised when treating acute EDC and complete resection should be emphasized during the operation to avoid neglecting the smaller cysts. Meanwhile, for non-ruptured high-tension EDC, fenestrating decompression can help reduce the degree of surgical difficulty.

In summary, after EDC surgery, particular consideration should be given to determining whether the case is one of recurrent EDC where esophageal tumors were rediscovered. Moreover, close follow-up should be emphasized. 


\section{Acknowledgements}

We would like to thank the efforts of Yihua Zhao, the pathologist from Beijing Tongren Hospital; with her help, we secured the patient's first EDC paraffin specimen (1982). We are also grateful to pathologist Rui Xu from Beijing Friendship Hospital and thank her for producing and analyzing the pathological sections.

\section{Footnote}

Conflicts of Interest: The authors have no conflicts of interest to declare.

Informed Consent: Written informed consent was obtained from the patients for the publication of this manuscript and the accompanying image.

\section{References}

1. Robison RJ, Pavlina PM, Scherer LR, et al. Multiple esophageal duplication cysts. J Thorac Cardiovasc Surg 1987;94:144-7.

2. Wang D, Du LC, Wang QX, et al. Esophagectomy for a rapidly progressing esophageal duplication cyst. ANN THORAC SURG 2015;99:e79-81.

3. Pisello F, Geraci G, Arnone E, et al. Acute onset of esophageal duplication cyst in adult. Case report. G Chir 2009;30:17-20.

4. Abu-Zaid A, Azzam A. Images in clinical medicine.

Cite this article as: Duan X, Cui Y, He Y, Xu S. Acute attack of recurrent esophageal duplication cyst in an adult: case report and literature review. J Thorac Dis 2018;10(5):E335-E339. doi: $10.21037 /$ jtd.2018.04.89
Esophageal duplication cyst. N Engl J Med 2014;371:e36.

5. Neo EL, Watson DI, Bessell JR. Acute ruptured esophageal duplication cyst. Dis Esophagus 2004;17:109-11.

6. Al-Sadoon H, Wiseman N, Chernick V. Recurrent thoracic duplication cyst with associated mediastinal gas. Can Respir J 1998;5:149-51.

7. Gatzinsky P, Fasth S, Hansson G. Intramural oesophageal cyst with massive mediastinal bleeding. A case report. Scand J Thorac Cardiovasc Surg 1978;12:143-5.

8. Nakahara K, Fujii Y, Miyoshi S, et al. Acute symptoms due to a huge duplication cyst ruptured into the esophagus. Ann Thorac Surg 1990;50:309-11.

9. Kang CU, Cho DG, Cho KD, et al. Thoracoscopic stapled resection of multiple esophageal duplication cysts with different pathological findings. Eur J Cardiothorac Surg 2008;34:216-8.

10. Dai ZJ, Kang HF, Lin S, et al. Esophageal cancer with esophageal duplication cyst. Ann Thorac Surg 2013;96:e15-6.

11. Cheng TY, Chen JH, Jan IS, et al. Esophageal duplication cyst presenting as a submucosal tumor: diagnosis by endoscopic ultrasound-guided fine-needle aspiration. Endoscopy 2006;38 Suppl 2:E30-1.

12. Castelijns PS, Woensdregt K, Hoevenaars B, et al. Intraabdominal esophageal duplication cyst: A case report and review of the literature. World J Gastrointest Surg 2014;6:112-6.

13. Mou Y, Wen D, Liu Q, et al. Endoscopic resection of an esophageal duplication cyst with spraying of anhydrous alcohol. Endoscopy 2015;47 Suppl 1 UCTN:E348-9. 